\title{
Hallazgo histopatológico de Strongyloides stercoralis en enfermedad de Crohn: reporte de caso
}

\section{Histopathologic finding of Strongyloides stercoralis in a patient with Crohn's disease: Case report}

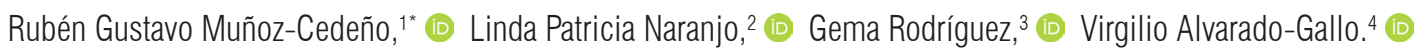

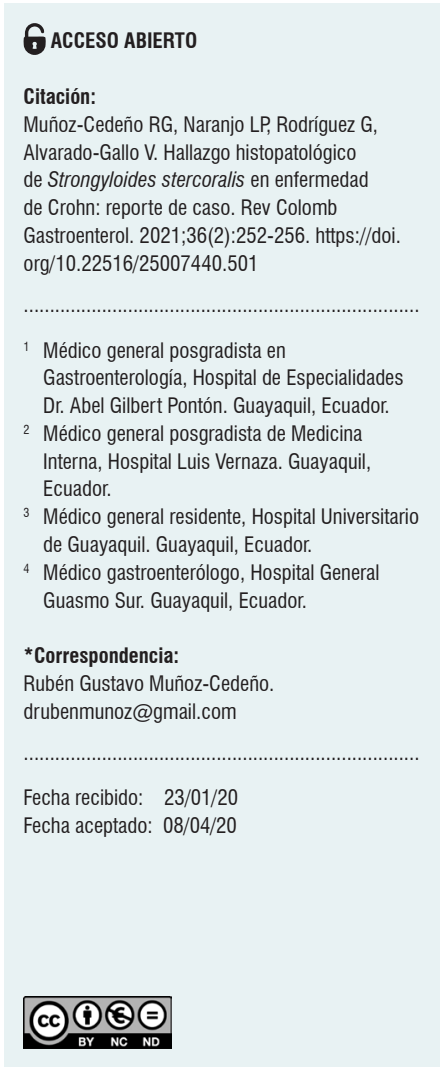

\begin{abstract}
Resumen
Caso clínico: se describe un caso clínico poco frecuente en un paciente inmunocomprometido con hallazgo histopatológico de infestación parasitaria. Es un paciente masculino de edad media que habita en zona subtropical con diagnóstico de enfermedad de Crohn tratado con corticoide e inmunomoduladores, presentaba dolor abdominal y anemia crónica de 1 año de evolución, analítica negativa para parásitos, reactantes de fase aguda normales, gastroscopia y colonoscopia previas (6 meses) sin hallazgos relevantes. Por la persistencia del cuadro clínico se repitieron los estudios endoscópicos en los que se visualizaron hemorragias subepiteliales con resultados histopatológicos de Strongyloides stercoralis. Conclusión: en el contexto de un paciente inmunocomprometido, en zona endémica y con evolución tórpida, debe obligar a realizar un diagnóstico diferencial en el que se debe sospechar siempre de infestación parasitaria. Aunque la endoscopia no se necesita para el diagnóstico de estrongiloidiasis, su intervención puede ser oportuna.
\end{abstract}

\section{Palabras clave}

Nematodos, Strongyloides stercoralis, inmunocomprometido, hematemesis, enfermedad de Crohn.

\begin{abstract}
Clinical case: The following is a rare clinical case in an immunocompromised patient with histopathological findings of parasitic infestation. The patient is a middle-aged male who lives in a subtropical area and has a diagnosis of Crohn's disease treated with corticosteroids and immunomodulators. The patient presented with abdominal pain and chronic anemia for 1 year, with negative laboratory tests for parasites and normal acute phase reactants. Gastroscopy and colonoscopy were performed before the consultation ( 6 months) without relevant findings. Due to the persistence of the symptoms, endoscopic studies were repeated, finding subepithelial bleeding with histopathological results of Strongyloides stercoralis. Conclusion: In the context of an immunocompromised patient living in an endemic area and with a torpid evolution, a differential diagnosis should be made always suspecting a parasitic infestation. Although endoscopy is not necessary to diagnose strongyloidiasis, its use may be convenient.
\end{abstract}

\section{Keywords}

Nematode infections; Strongyloides stercolaris; Immunocompromised host; Hematemesis; Crohn's Disease.

\section{INTRODUCCIÓN}

La colitis por Strongyloides stercoralis es una enfermedad grave, pero fácilmente curable con una alta tasa de mortalidad si no se trata. Puede permanecer hasta varias décadas y desarrollar una colitis crónica similar a la observada en la enfermedad inflamatoria intestinal (EII). Las zonas tropicales y subtropicales prestan las condiciones adecuadas para su desarrollo.

Las manifestaciones de la infección pueden variar desde la eosinofilia asintomática en el huésped inmunocompe- 
tente a la enfermedad diseminada con choque séptico en el huésped inmunocomprometido, y esta última forma es la presentación de nuestro caso, como hallazgos histopatológicos en la enfermedad de Crohn.

\section{PRESENTACIÓN DE CASO}

Se trata de un paciente masculino de 55 años de edad, mestizo, comerciante, en tratamiento con corticoides e inmunomoduladores (azatioprina) por enfermedad de Crohn con antecedentes quirúrgicos de apendicectomía y colecistectomía en 2015. En seguimiento por dolor abdominal y anemia crónica, acudió a urgencias con un cuadro clínico de melena intermitente de 1 mes de evolución que se agudizó con hematoquecia, palidez marcada, astenia y artralgias de 1 semana. Tuvo la siguiente analítica: hemoglobina: $5,80 \mathrm{~g} / \mathrm{dL}$, hematocrito: $18,60 \%$ y plaquetas: 340000 $\mathrm{mm}^{3}$ (Tabla 1). En el examen físico se encontró palidez marcada con signos de descompensación hemodinámica e hipotensión (presión arterial: 90/40 $\mathrm{mm} \mathrm{Hg}$ ); se sospechó de una probable reactivación de la enfermedad, por lo cual se administró metilprednisolona $60 \mathrm{mg}$, antibióticos y hemoderivados, y se obtuvo la mejoría clínica del paciente. En la analítica se solicitaron patrones reactantes de la fase aguda dentro de lo normal, coproparasitario y coprocultivo, todos con resultados normales y negativos para microorganismos. Durante su internación se realizó una gastroscopia y se encontraron hemorragias subepiteliales, erosiones y úlceras en el cuerpo, antro e incisura; además de páncreas aberrante y duodeno hasta su segunda porción con hemorragias subepiteliales y edema; en la colonoscopia se evidenciaron hemorragias subepiteliales en todo su trayecto hasta el ciego. Por esta razón, se tomaron muestras a lo largo de todo el tubo digestivo (estomago, intestino delgado y colon) (Figuras 1 y 2 ).

En espera de los resultados de la biopsia, 20 días después de su ingreso, el paciente debutó con evacuaciones líquidas amarillentas, dolor abdominal difuso y fiebre. Se realizó un ultrasonido abdominal sin signos relevantes, analítica con leucocitosis y neutrofilia. En su evolución presentó lesiones dérmicas fluctuantes pruriginosas diseminadas (eritrodermia) valoradas por dermatología con biopsias de piel no concluyente, además de disfonía y tos, que dieron la impresión de una laringotraqueítis.

El paciente en su evolución tórpida presentó hipotensión: 90/60 mm Hg, taquicardia: 140 latidos por minuto (lpm), taquipnea: 38 respiraciones por minuto (rpm), hipoxemia: $92 \%$ con apoyo de oxígeno, astenia muy marcada sin datos de sangrado digestivo agudo, deshidratación hipotónica moderada, oligoanuria, laboratorios de hiponatremia e hipocloremia, e hipoproteinemia sin repuesta a la expansión de volumen, pero con sensorio conservado. Estos datos fue-
Tabla 1. Datos de laboratorio de ingreso

\begin{tabular}{|cc|}
\hline Examen & Valor obtenido \\
\hline Leucocitos & $7,80 \times 10^{3} / \mu \mathrm{L}$ \\
\hline Neutrófilos & $60 \%$ \\
\hline Linfocitos & $22 \%$ \\
\hline Monocitos & $9,40 \%$ \\
\hline Eosinófilos & $7,40 \%$ \\
\hline Basófilos & $0,40 \%$ \\
\hline Eritrocitos & $2,08 \times 10^{4} / \mathrm{\mu L}$ \\
\hline Hemoglobina & $5,80 \mathrm{~g} / \mathrm{dL}$ \\
\hline Hematocrito & $18,60 \%$ \\
\hline Plaquetas & $340000 \times 10^{3}$ \\
\hline VSG & $15 \mathrm{~mm} / \mathrm{h}$ \\
\hline PCR & $4 \mathrm{mg} / \mathrm{L}$ \\
\hline Ferritina & $150 \mathrm{ng} / \mathrm{mL}$ \\
\hline
\end{tabular}

PCR: proteína C-reactiva; VSG: velocidad de sedimentación globular.

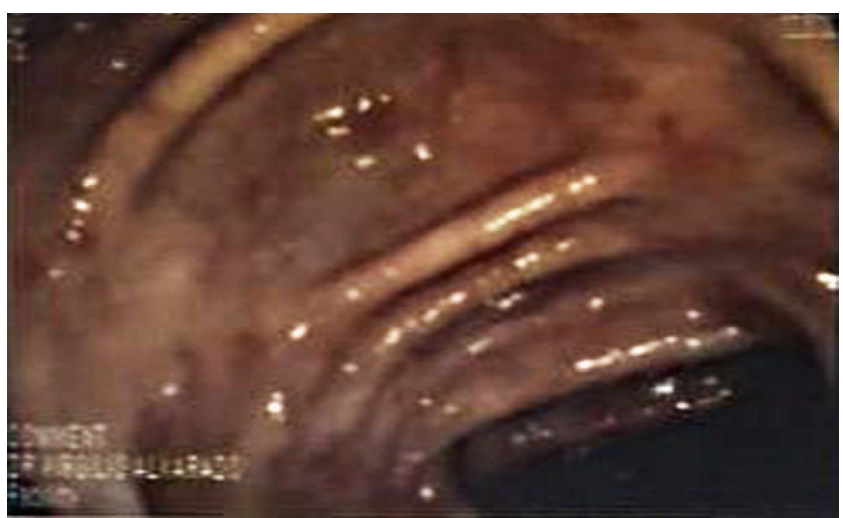

Figura 1. Colonoscopia: hemorragias subepiteliales y erosiones en el colon transverso.

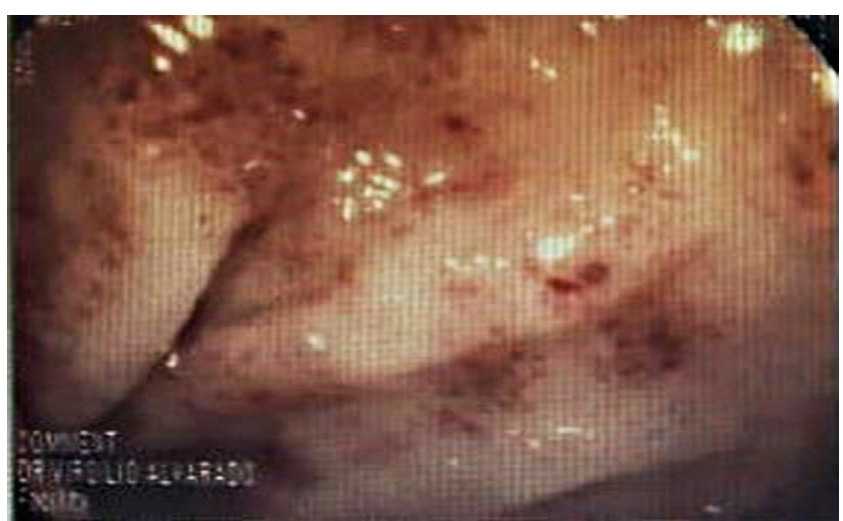

Figura 2. Colonoscopia: hemorragias subepiteliales y erosiones en el colon sigmoideo. 
ron compatibles con el síndrome de repuesta inflamatoria sistémica (SIRS) y se sospechó de sobreinfección bacteriana o fúngica, por lo que se decidió su paso a la unidad de cuidados intensivos (UCI); sin embargo, los familiares y el paciente no están de acuerdo y solicitaron el alta a petición. El paciente reingresó a las 8 horas posteriores a su egreso con síndrome de dificultad respiratoria aguda (SDRA), hipoxemia grave y choque séptico refractario al soporte inotrópico, por lo que finalmente el paciente falleció.

Se revisaron los resultados de las biopsias obtenidas por vía endoscópica, las cuales evidenciaron presencia de $S$. stercoralis en todas las muestras enviadas: estómago, duodeno, colon y recto.

\section{DISCUSIÓN}

La estrongiloidiasis es causada por un nematodo, llamado Strongyloides. Existen 52 especies, pero la mayoría no infecta a los humanos. El patógeno humano más común y distribuido globalmente es el S. stercoralis, que afecta a 100 millones de personas. La otra especie en frecuencia es Strongyloides fuelleborni, la cual se encuentra esporádicamente en África y Nueva Guinea. El S. stercoralis es endémico en los trópicos y subtrópicos, sudeste asiático, América Latina, África subsahariana y en el sudeste de Estados Unidos, y ocurre esporádicamente en áreas templadas (1).

La fisiopatología se da porque la larva se desarrolla en su estado adulto en la mucosa intestinal del duodeno y yeyuno; la hembra adulta produce por patogénesis alrededor de 12 huevos diarios, que luego eclosionan a larvas rabditoides, por eso en la mucosa intestinal solo se encuentran hembras adultas, larvas rabditoides, huevos, muy raramente, larvas filariformes y nunca machos adultos. Los cambios histopatológicos que causa en la mucosa intestinal fueron descritos en 1962 por De Paola, que son las lesiones intestinales en enteritis catarral, enteritis edematosa y enteritis ulcerativa, según el tipo de infiltrado inflamatorio, la atrofia de las vellosidades y la presencia de úlcera $(2,3)$.

La forma de presentación y la evolución de esta infección están determinadas por la interacción entre el hospedero y el parásito. La activación de la respuesta inmune celular de linfocitos T helper 2 (Th2), de la respuesta inmune humoral o la alteración de la barrera de la mucosa favorecen la trasformación de la larva rabditoide en filariforme, lo que se considera sindrome de autoinfección, que produce una reinfección en el propio huésped. Al atravesar la mucosa del colon, la larva filariforme puede arrastrar bacterias y hongos distribuyéndolos por el resto del organismo, causando sepsis bacterianas o fúngicas y meningitis por gramnegativos. Esta capacidad de autoinfección puede dar lugar a una enfermedad crónica de décadas de duración. El cuadro respiratorio se produce por la infiltración larvaria de los espa- cios vasculares y alveolares, lo que resulta en edema pulmonar, bronconeumonía y hemorragia alveolar. La muerte intrapulmonar de los parásitos causa intensa inflamación y SDRA, y la mortalidad puede alcanzar hasta un $80 \%(4,5)$.

La diseminación conlleva una alta mortalidad (70\%-90\%). La infección por el nematodo $S$. stercoralis es potencialmente letal por su capacidad para producir una autoinfección devastadora (hiperinfección/diseminación), en particular en el huésped inmunodeprimido, como son los pacientes virus de la inmunodeficiencia humana (VIH), que producen niveles elevados de interferón gamma (INF- $\gamma$ ), niveles séricos disminuidos de interleucina 4 (IL-4) y, consecuentemente, de inmunoglobulina $\mathrm{E}$ ( $\mathrm{IgE}$ ), lo que hace posible una enfermedad más grave y la aparición de este síndrome $(2,4,5)$.

Esta infección crónica puede ser clínicamente inaparente o manifestarse por síntomas cutáneos, gastrointestinales o pulmonares descritos en numerosos casos de inmunosupresión (VIH, alcoholismo, trasplante de órganos, uso de corticoides) $(6,7)$ con alta probabilidad de desarrollar hiperinfección, ya que ciertos fármacos citotóxicos dañan la inmunidad celular. La fisiopatología subyacente a estos factores de riesgo, ya sea relacionada con la enfermedad o inducida iatrogénicamente, es un sistema inmune comprometido que conduce a la disfunción de las células Th2 auxiliares; por tanto, es importante detectar y erradicar el Strongyloides antes del inicio de la terapia inmunosupresora (8).

Alrededor de un tercio de los pacientes con estrongiloidiasis se hallan asintomáticos. La concentración sérica de la IgE es elevada en estos entornos (9). Los síntomas gastrointestinales incluyen diarrea, dolor abdominal, vómito y sangrado gastrointestinal masivo secundario a la presencia de úlceras duodenales, además de oclusión intestinal e íleo. Los síntomas respiratorios incluyen principalmente tos $y$ disnea. En los síndromes de hiperinfección y diseminación, la afección pulmonar se presenta como síndrome de insuficiencia respiratoria aguda (SIRA) (10-12).

La eosinofilia se correlaciona con la migración de la larva y puede estar presente en el $83 \%-92 \%$ de los pacientes con autoinfección; sin embargo, no está presente universalmente, pero puede ser la única pista. Puede estar ausente en casos de hiperinfección o uso de fármacos inmunosupresores $(13,14)$. Para el diagnóstico se deben recolectar 2 muestras de heces concentradas para detectar la presencia de larvas rabditiformes, pruebas serológicas (método de enzimoinmunoanálisis de adsorción [ELISA] con detección de inmunoglobulina $\mathrm{G}$ [IgG]), aspiración duodenoyeyunal y PCR en heces (15). Lo que se esperaría ver en el hemograma es la eosinofilia, que orientaría la sospecha de parásito, pero cuando se ha desarrollado diseminación no hay eosinofilia y el recuento de leucocitos es variable. La endoscopia alta no se necesita para el diagnóstico de estrongiloidiasis; sin embargo, algunas publicaciones men- 
cionan que puede dar lugar a una amplia gama de características endoscópicas $(16,17)$.

Nuestro paciente mantuvo el tratamiento con corticoides e inmunomoduladores (azatioprina) aproximadamente por 1 año. Ante la sospecha de reactivación, se inició la administración de corticoides a dosis de inducción con una aparente mejoría, que desvaneció en primera instancia la sospecha de una infestación parasitaria, sobre todo por coproparasitarios seriados negativos y ausencia de larvas a la visión endoscópica; y recibió antibióticos de amplio espectro asumiendo una posible sobreinfección bacteriana o fúngica .Cabe resaltar que en los laboratorios solicitados nunca se evidenció eosinofilia marcada, posiblemente debido a su inmunosupresión. La confirmación de la presencia de este nematodo fue a través de resultados de biopsia en todas las muestras tomadas del estómago, duodeno y colon. Sin embargo, la tórpida evolución y deterioro progresivo impidió buscar microorganismos atípicos o estudios en el líquido alveolar. En este caso, no sabremos si se pudo haber evitado el desenlace fatal instaurando el tratamiento a base de ivermectina o albendazol en las condiciones graves que estaba nuestro paciente.

Ante la no respuesta al tratamiento convencional (corticoides) en pacientes inmunocomprometidos, es necesaria la búsqueda de este tipo de parásito, especialmente en zonas de mayor riesgo o prevalencia. Como se sabe que las pruebas diagnósticas podrían ser negativas, en este caso se puede administrar ivermectina en forma empírica. El tratamiento con ivermectina se recomienda para la estrongiloidiasis no complicada (grado 1A), se receta como 2 dosis únicas de $200 \mu \mathrm{g} / \mathrm{kg}$ administradas en 2 días consecutivos. En pacientes con enfermedad diseminada (hiperinfección), se sugiere la administración prolongada de ivermectina (grado 2C) $200 \mu \mathrm{g} / \mathrm{kg} /$ día durante al menos 5 a 7 días o se puede combinar con albendazol $400 \mathrm{mg} /$ por vía oral (VO) 2 veces al día durante 3 a 7 días. El tratamiento debe administrase diariamente hasta que los síntomas se resuelvan y las pruebas de heces sean negativas durante al menos 2 semanas (18-20).

\section{CONCLUSIONES}

En un paciente inmunocomprometido en una zona endémica con evolución tórpida, exámenes coprológicos negativos y reactantes de fase aguda negativos se debe tener la alta sospecha de infestación parasitaria e iniciar de manera empírica con tratamiento antihelmíntico y, de ser necesario, repetir lo estudios endoscópicos, ya que no se puede establecer el tiempo de infestación ni los cambios morfológicos entre un estudio y otro. Aunque la endoscopia no se necesita para el diagnóstico de estrongiloidiasis, su intervención puede ser oportuna, como lo fue en nuestro caso.

\section{Conflictos de interés}

No existen conflictos de intereses.

\section{Fuentes de financiación}

Propias de los autores.

\section{REFERENCIAS}

1. Schär F, Trostdorf U, Giardina F, Khieu V, Muth S, Marti $\mathrm{H}$, et al. Strongyloides stercoralis: Global Distribution and Risk Factors. PLoS Negl Trop Dis. 2013;7(7):e2288. https://doi.org/10.1371/journal.pntd.0002288

2. Newberry AM, Williams DN, Stauffer WM, Boulware DR, Hendel-Paterson BR, Walker PF. Strongyloides hyperinfection presenting as acute respiratory failure and gramnegative sepsis. Chest. 2005;128(5):3681-4. https://doi.org/10.1378/chest.128.5.3681

3. Arévalo Suarez F, Cerrillo Sánchez G. Strongyloides stercoralis: Hallazgos Histopatológicos en Mucosa Duodenal 1999-2005. Rev Gastroenterol Perú. 2006;26(1):44-8.

4. Gorman SR, Craven DE. Images in clinical medicine. Strongyloides stercoralis hyperinfection. N Engl J Med. 2008;359(11):e12. https://doi.org/10.1056/NEJMicm066791

5. Upadhyay D, Corbridge T, Jain M, Shah R. Pulmonary hyperinfection syndrome with Strongyloides stercoralis.
Am J Med. 2001;111(2):167-9. https://doi.org/10.1016/s0002-9343(01)00708-2

6. Woodring JH, Halfhill H 2nd, Reed JC. Pulmonary strongyloidiasis: clinical and imaging features. AJR Am J Roentgenol. 1994;162(3):537-42. https://doi.org/10.2214/ajr.162.3.8109492

7. Kim JH, Kim DS, Yoon YK, Sohn JW, Kim MJ. DonorDerived Strongyloidiasis Infection in Solid Organ Transplant Recipients: A Review and Pooled Analysis. Transplant Proc. 2016;48(7):2442-2449. https://doi.org/10.1016/j.transproceed.2015.11.045

8. Fardet L, Généreau T, Cabane J, Kettaneh A. Severe strongyloidiasis in corticosteroid-treated patients. Clin Microbiol Infect. 2006; 12(10):945-7. https://doi.org/10.1111/j.1469-0691.2006.01443.x

9. Concha R, Harrington W Jr, Rogers AI. Intestinal strongyloidiasis: recognition, management, and determinants 
of outcome. J Clin Gastroenterol. 2005;39(3):203-11. https://doi.org/10.1097/01.mcg.0000152779.68900.33

10. Robinson RD, Lindo JF, Neva FA, Gam AA, Vogel P, Terry SI, et al. Immunoepidemiologic studies of Strongyloides stercoralis and human T lymphotropic virus type I infections in Jamaica. J Infect Dis. 1994;169(3):692-6. https://doi.org/10.1093/infdis/169.3.692

11. Scowden EB, Schaffner W, Stone WJ. Overwhelming strongyloidiasis: an unappreciated opportunistic infection. Medicine (Baltimore). 1978;57(6):527-44.

12. Strazzella WD, Safirstein BH. Asthma due to parasitic infestation. N J Med. 1989;86(12):947-9.

13. Woodring JH, Halfhill H 2nd, Berger R, Reed JC, Moser N. Clinical and imaging features of pulmonary strongyloidiasis. South Med J. 1996;89(1):10-9. https://doi.org/10.1097/00007611-199601000-00002

14. Lessnau KD, Can S, Talavera W. Disseminated Strongyloides stercoralis in human immunodeficiency virus-infected patients. Treatment failure and a review of the literature. Chest. 1993;104(1):119-22. https://doi.org/10.1378/chest.104.1.119

15. Sharifdini M, Mirhendi H, Ashrafi K, Hosseini M, Mohebali M, Khodadadi H, et al. Comparison of Nested Polymerase Chain Reaction and Real-Time Polymerase
Chain Reaction with Parasitological Methods for Detection of Strongyloides stercoralis in Human Fecal Samples. Am J Trop Med Hyg. 2015;93(6):1285-91. https://doi.org/10.4269/ajtmh.15-0309

16. Sreenivas DV, Kumar A, Kumar YR, Bharavi C, Sundaram C, Gayathri K. Intestinal strongyloidiasis--a rare opportunistic infection. Indian J Gastroenterol. 1997;16(3):105-6.

17. Thompson BF, Fry LC, Wells CD, Olmos M, Lee DH, Lazenby AJ, et al. The spectrum of GI strongyloidiasis: an endoscopic-pathologic study. Gastrointest Endosc. 2004;59(7):906-10. https://doi.org/10.1016/s0016-5107(04)00337-2

18. Drugs for Parasitic Infections. Treatment Guidelines from The Medical Letter. 2013;11(Suppl):e1-e31.

19. Henriquez-Camacho C, Gotuzzo E, Echevarria J, White AC Jr, Terashima A, Samalvides F, et al. Ivermectin versus albendazole or thiabendazole for Strongyloides stercoralis infection. Cochrane Database Syst Rev. 2016;2016(1):CD007745. https://doi.org/10.1002/14651858.CD007745.pub3

20. Zaha O, Hirata T, Kinjo F, Saito A, Fukuhara H. Efficacy of ivermectin for chronic strongyloidiasis: two single doses given 2 weeks apart. J Infect Chemother. 2002;8(1):94-8. https://doi.org/10.1007/s101560200013 